\title{
MODELAGEM DE ÁREAS SUSCETÍVEIS A MOVIMENTOS DE MASSA: AVALIAÇÃO COMPARATIVA DE TÉCNICAS DE AMOSTRAGEM, APRENDIZADO DE MÁQUINA E MODELOS DIGITAIS DE ELEVAÇÃO
}

\author{
MODELING TO LANDSLIDES SUSCEPTIBLE AREAS: COMPARATIVE EVALUATION OF \\ SAMPLING TECHNIQUES, MACHINE LEARNING AND DIGITAL ELEVATION MODELS
}

\author{
Renata PACHECO QUEVEDO ${ }^{1}$; Laurindo Antonio GUASSELLI ${ }^{2}$; Guilherme GARCIA \\ DE OLIVEIRA $^{3}$; Luis Fernando CHIMELO RUIZ ${ }^{1}$ \\ ${ }^{1}$ Programa de Pós-Graduação em Sensoriamento Remoto - PPGSR. Centro Estadual de Pesquisas em Sensoriamento Remoto e \\ Meteorologia - CEPSRM. Universidade Federal do Rio Grande do Sul - UFRGS. Av. Bento Gonçalves, $n^{\circ}$ 9.500, Porto Alegre - RS. \\ E-mails: renatapquevedo@gmail.com; ruiz.ch@gmail.com \\ ${ }^{2}$ Departamento Geografia, Instituto de Geociências, Programa de Pós-Graduação em Sensoriamento Remoto, UFRGS. Av. Bento \\ Gonçalves, nº 9.500, Porto Alegre - RS. E-mail: laurindo.guasselli@ufrgs.br \\ ${ }^{3}$ Departamento Interdisciplinar. Universidade Federal do Rio Grande do Sul - UFRGS. RS-030, km 92, nº 11.700, Tramandaí - RS. \\ E-mail: g.g.oliveira10@gmail.com

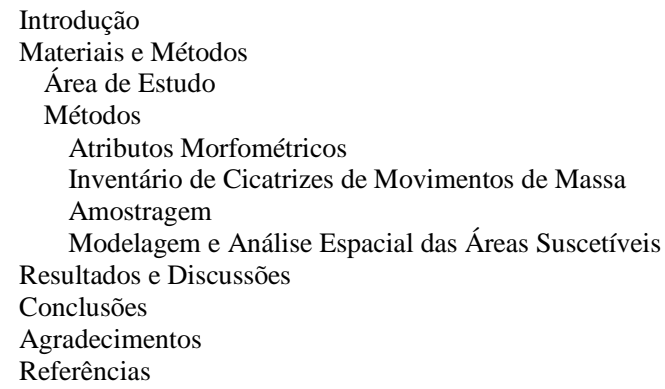

RESUMO - Métodos de redes neurais artificiais (RNA) e random forest (RF) apresentam bom desempenho para mapear áreas suscetíveis a movimentos de massa. Entretanto, a modelagem é sensível à amostragem, à escala do modelo digital de elevação (MDE), ao conjunto das variáveis explicativas e aos seus parâmetros de ajuste, influenciando o mapa final. O objetivo deste artigo foi avaliar e comparar técnicas de amostragem e MDE para a modelagem de áreas suscetíveis a movimentos de massa, utilizando RNA e RF. Foram extraídas sete variáveis explicativas, a partir dos MDEs ALOS-PALSAR e ASTER GDEM, consideradas duas áreas amostrais e comparados dois métodos de reamostragem para redução do conjunto de treinamento. As acurácias apresentaram valores entre 0,88 e 0,94, demonstrando que os modelos RNA e RF, combinados com os MDEs ALOS-PALSAR e ASTER GDEM, possibilitam identificar áreas suscetíveis a movimentos de massa. Na modelagem se destacaram as seguintes variáveis explicativas: altitude, declividade, fator LS e profundidade do vale. A definição de uma área amostral mais abrangente para coleta de amostras de não ocorrência aumentou a acurácia e a capacidade de generalização dos modelos. A redução do conjunto amostral de treinamento diminuiu o tempo de processamento, sem interferir significativamente na acurácia do mapa.

Palavras-chave: redes neurais artificiais, random forest, ALOS-PALSAR, ASTER GDEM, Bacia Hidrográfica do Rio Rolante.

\begin{abstract}
Artificial neural network (ANN) and random forest (RF) methods present good performance to map landslides susceptible areas. However, the landslides modeling is sensitive to the sampling, the scale of the digital elevation models (DEM), to the set of terrain attributes and their adjustment parameters, influencing on the final map and the models generalization power. This article aimed to evaluate and compare sampling techniques and DEM for modeling landslides susceptible areas, using ANN and RF. The study area corresponds to the Rolante River Basin. Seven attributes of the terrain were extracted from DEM ALOS-PALSAR and DEM ASTER GDEM. These samples were selected considering two areas and comparing two resampling methods to reduce the training set of the models. All combinations resulted in values for accuracy between 0.88 and 0.94 . This demonstrated that ANN and RF models, combined with ALOS-PALSAR and ASTER GDEM, serve the purpose of identifying landslides susceptible areas. In general, the terrain attributes that stood out in the modeling were: elevation, slope, LS factor, and valley depth. Concluding that the larger sampling areas for non-occurrence increased the accuracy and the generalization capacity. In addition, the training sample reduction decreased the processing time, without significantly increasing the maps accuracy.
\end{abstract}

Keywords: artificial neural network, random forest, ALOS-PALSAR, ASTER GDEM, Rolante River Basin.

\section{INTRODUÇÃO}

Os movimentos de massa podem ser número de mortes devido à ocorrência de desencadeados por terremotos, precipitações extremas ou atividades antrópicas e estão entre os desastres que causam maior número de vítimas fatais. No período entre 2004 e 2016, o movimentos de massa ao redor do mundo foi de 4.862 (Froude \& Petley, 2018). No Brasil, os eventos de Itajaí, em Santa Catarina, em 2008, e da região serrana do Rio de Janeiro, em 2011, 
foram responsáveis por um elevado número de vítimas, 135 e 917 mortes, respectivamente.

Devido a este cenário, foi elaborado o Plano Nacional de Gestão de Riscos e Resposta a Desastres Naturais no ano de 2012, com o objetivo de mitigar os riscos das áreas suscetíveis a desastres ocasionados por fenômenos naturais (BRASIL, 2012; CEPED UFSC, 2013).

O mapeamento de suscetibilidade é uma importante ferramenta de auxílio aos gestores locais para o planejamento urbano, de forma a evitar a ocupação de áreas suscetíveis a movimentos de massa ou inundações, além de possibilitar a reorganização do espaço urbano e identificar áreas prioritárias para instalação de sistemas de alerta (Aditian et al., 2018; Oliveira et al., 2018).

O aprendizado de máquinas, como redes neurais artificiais (RNA) e Random Forest (RF), se apresenta como uma ferramenta importante para esse tipo de mapeamento (Kawabata \& Bandibas, 2009; Pradhan \& Lee, 2010; Dou et al., 2015; Chen et al., 2017; Ada \& San, 2018; Aditian et al. 2018).

Modelagem por RNA para mapeamento de áreas suscetíveis a movimentos de massa foi realizada por Kawabata \& Bandibas (2009), a partir do uso de dois MDEs, que demonstraram resultados com acurácia superior a 0,9, sendo 0,937 para o MDE de $15 \mathrm{~m}$ e 0,944 para o MDE de 55 m. Pradhan \& Lee (2010) obtiveram acurácia de 0,83 e a variável explicativa que mais contribuiu na modelagem foi a declividade. Dou et al. (2015) selecionaram seis fatores condicionantes dentre 14 disponíveis e obtiveram acurácia igual a 0,82 , enquanto com 14 variáveis, foi de 0,73. Chen et al. (2017) compararam os métodos maximum entropy, support vector machine (SVM) e RNA, e apresentaram resultados em que a RNA obteve maior acurácia $(0,824)$ e a altitude foi um dos fatores mais importantes. Aditian et al. (2018) compararam três métodos diferentes para modelagem e mapeamento de suscetibilidade: bivariate frequency ratio, multivariate logistic regression e RNA. Dentre eles, o modelo que apresentou maior taxa de sucesso foi a RNA, com acurácia de 0,734. Ada \& San (2018) compararam as técnicas SVM e RF, e obtiveram acurácias entre 0,82 e 0,87, respectivamente.

Os métodos RF e RNA apresentam um desempenho satisfatório para mapear áreas suscetíveis a movimentos de massa. Entretanto, por serem métodos empíricos, a modelagem de áreas de movimentos de massa por meio das técnicas de aprendizado de máquina é sensível à amostragem, à escala do MDE, ao conjunto de variáveis explicativas e aos seus parâmetros de ajuste, influenciando o mapa final e o poder de generalização dos modelos. Logo, é importante avaliar o desempenho desses modelos em função de diferentes conjuntos amostrais e fontes de dados de entrada, de modo a analisar sua capacidade de generalização para áreas maiores, bem como a sensibilidade dos modelos em relação aos atributos de entrada.

Assim, o objetivo deste artigo foi avaliar o desempenho e a sensibilidade da modelagem de áreas suscetíveis a movimento de massa considerando: (i) os métodos de aprendizado de máquina RNA e RF; (ii) duas áreas para coleta de amostras de não ocorrência, combinadas com dois métodos de reamostragem dos conjuntos de treinamento; e (iii) usando os MDEs ALOSPALSAR e ASTER GDEM para obtenção das variáveis explicativas.

\section{MATERIAIS E MÉTODOS}

\section{Área de Estudo}

Este estudo foi aplicado à área da Bacia Hidrográfica do Rio Rolante (BHRR), Região Hidrográfica do Guaíba. Encontra-se na porção nordeste do estado do Rio Grande do Sul, entre as latitudes $29^{\circ} 20^{\prime} 43^{\prime \prime}$ 'S e $29^{\circ} 43^{\prime} 33^{\prime \prime} \mathrm{S}$ e as longitudes $50^{\circ} 18^{\prime} 48^{\prime \prime} O$ e $50^{\circ} 43^{\prime} 06^{\prime \prime O}$ (Figura 1). A área de drenagem da BHRR é de aproximadamente 830 $\mathrm{km}^{2}$, com altitudes entre 19 e $997 \mathrm{~m}$. De acordo com Rossato (2011), a região apresenta um clima subtropical muito úmido, com precipitação entre 1700 e 2000 mm anuais, com ingresso de sistemas frontais de precipitação e influência da orografia.
Na BHRR, ocorreu um evento extremo de precipitação, em 05 de janeiro de 2017, que desencadeou mais de duzentas cicatrizes de movimentos de massa (Figura 2).

As chuvas apresentaram significativa concentração espaço-temporal, na região das cabeceiras da BHRR, na sub-bacia do rio Mascarada. Devido à falta de pluviômetros oficiais na região, foram consultados medidores particulares, os quais apresentaram, em poucas horas, valores entre 90 e $272 \mathrm{~mm}$, diferentemente da estimativa oficial que foi de $50 \mathrm{~mm}$ (SEMA, 2017). 
As chuvas tiveram duração de quatro horas, entre as $14 \mathrm{~h}$ e as $18 \mathrm{~h}$, causando o deslocamento do material da encosta para o fundo do vale. Consequentemente, formaram-se barreiras no leito dos rios, houve aumento do nível das águas e da carga de energia retidos. Quando houve o rompimento dessas barreiras, uma consequente enxurrada atingiu o município de Rolante, causando diversas perdas e danos materiais (SEMA, 2017).

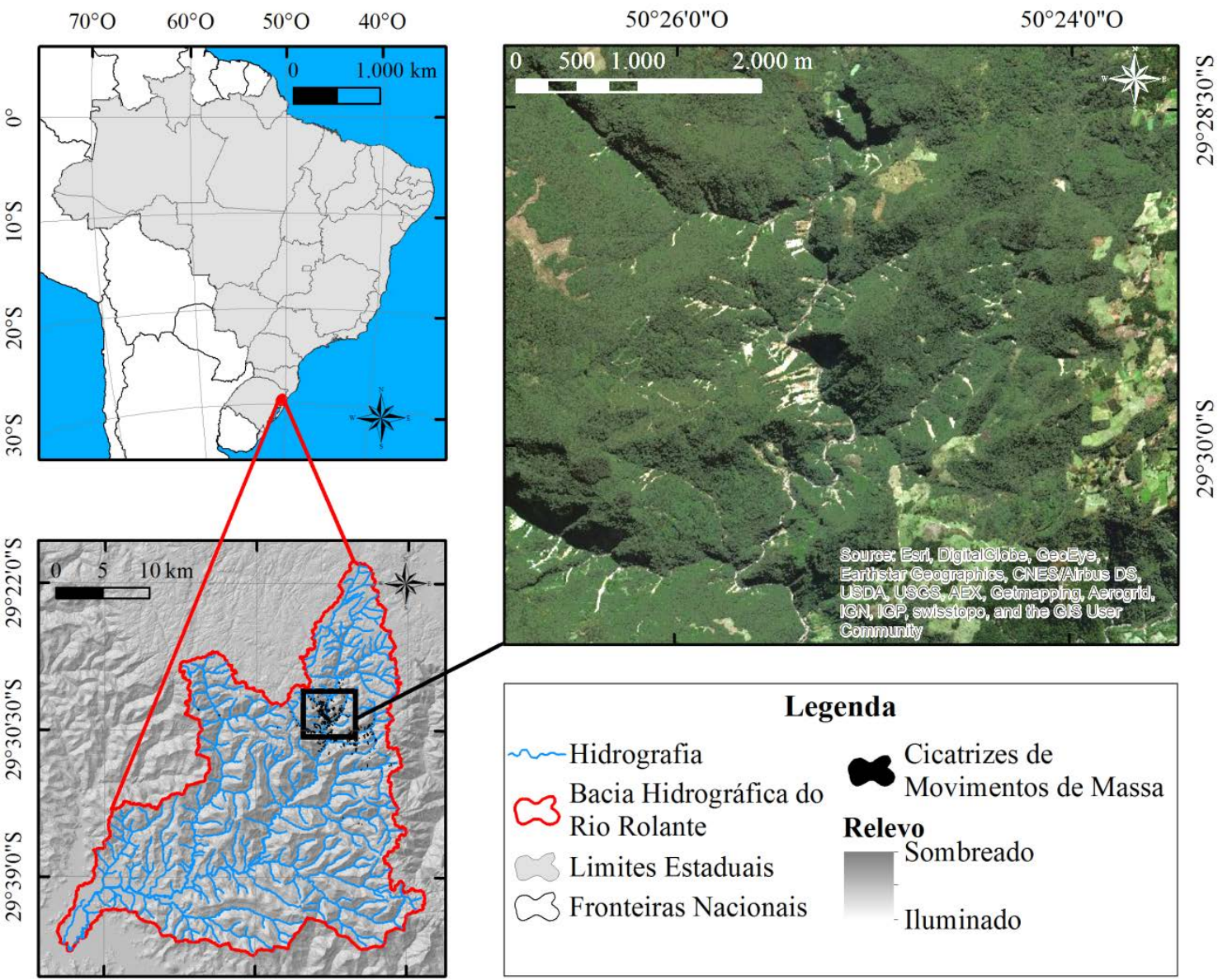

Figura 1 - Localização das cicatrizes de movimentos de massa, Bacia Hidrográfica do Rio Rolante, RS.

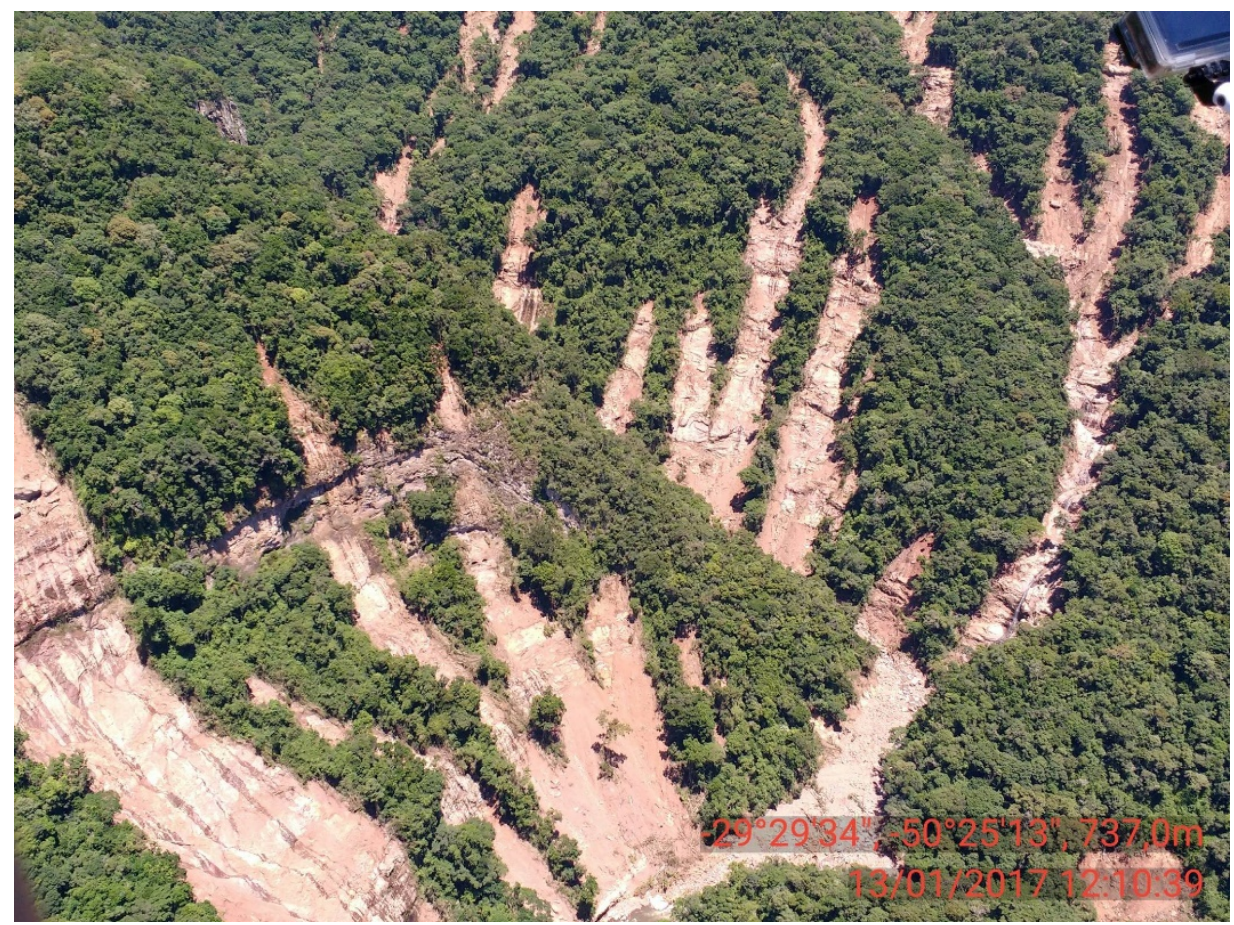

Figura 2 - Cicatrizes de movimentos de massa resultantes do evento extremo de precipitação de 05 de janeiro de 2017. Fonte: $2^{\circ}$ Pelotão de Polícia Ambiental (PATRAM) de Canela, RS, 13 de janeiro de 2017. 


\section{Métodos}

Os métodos foram estruturados em cinco etapas de processamento, conforme (Figura 3):

i) extração de variáveis explicativas a partir dos MDEs ALOS-PALSAR e ASTER GDEM; ii) pré-processamento e organização dos conjuntos amostrais; iii) treinamento e calibração dos modelos; iv) teste dos modelos; v) reclassificação dos modelos com melhor acurácia, para níveis de suscetibilidade em ambiente de Sistema de Informações Geográficas.

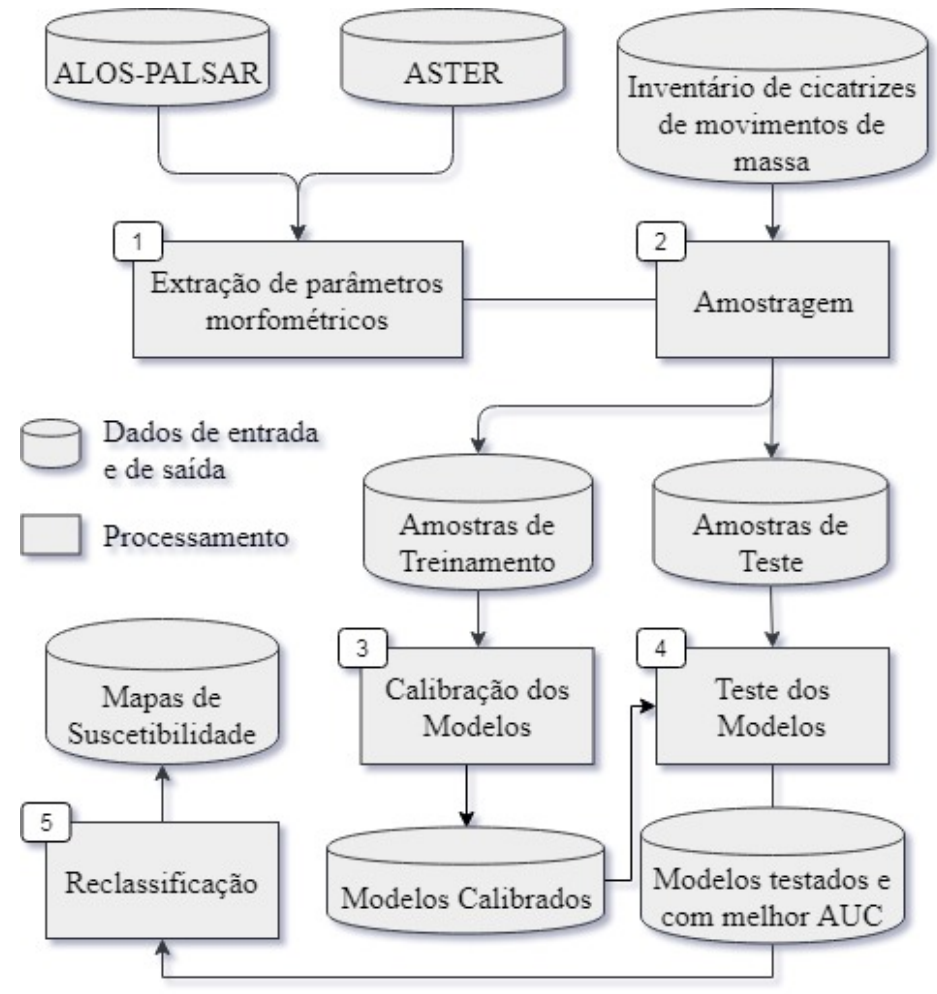

Figura 3 - Fluxograma da metodologia utilizando dois modelos digitais de altitude.

\section{Variáveis Explicativas}

Os MDEs ALOS-PALSAR e ASTER GDEM foram utilizados para a extração das variáveis explicativas, com resolução espacial de $12,5 \mathrm{~m}$ e $30 \mathrm{~m}$, respectivamente. O método de aquisição das imagens ALOS-PALSAR é a partir de um sensor micro-ondas, banda L (Phased Array type L-band Synthetic Aperture Radar) (JAXA), enquanto as imagens ASTER GDEM são adquiridas a partir de par estereoscópico de bandas localizadas na faixa do infravermelho próximo (ASTER GDEM, 2011).

As variáveis foram previamente analisadas considerando-se o evento extremo de 05 de janeiro de 2017 em Gameiro et al. (2019) e Quevedo et al. (2019). As onze variáveis consideradas foram analisadas conforme sua correlação com as áreas de ocorrência de movimentos de massa. Assim, foram selecionadas as sete variáveis explicativas que apresentaram maior correlação com ocorrência de movimentos de massa: altitude, declividade, curvaturas vertical e horizontal, relevo sombreado, fator LS e profundidade do vale.
A altitude se refere aos valores de elevação quanto a um referencial, representada em metros. A declividade representa a inclinação da vertente em graus, com influência direta na espessura do solo, ou seja, do material passível de movimentação (Meten et al., 2015). Quanto maior a declividade, maior tende a ser a suscetibilidade, apresentando um máximo entre 35 e $40^{\circ}$. Segundo Dai \& Lee (2002), a suscetibilidade diminui em declives maiores do que $40^{\circ}$, no entanto para Chen et al. (2016) a diminuição ocorre a partir de um ângulo máximo maior que $65^{\circ}$.

As curvaturas vertical e horizontal descrevem o formato da encosta, influenciando diretamente nas tensões de condução e resistência, e no grau de convergência ou divergência do escoamento da água e do material transportado. A curvatura vertical apresenta-se ao longo de uma linha formada pela intersecção de um plano vertical imaginário e a superfície do solo, valores negativos representam formas côncavas e valores positivos, formas convexas. A curvatura horizontal está relacionada à intersecção de um plano horizontal imaginário, sendo os valores 
negativos referentes a áreas convergentes e valores positivos, formas divergentes de escoamento (Meten et al., 2015).

O mapa de relevo sombreado demonstra o padrão geomorfológico, os lineamentos estruturais, a localização e o formato dos vales e encostas. O fator LS (Slope Length and Steepness Factor) apresenta o efeito da topografia na erosão do solo. Combina os fatores $\mathrm{S}$, que mede o efeito da inclinação da encosta, ou seja, a declividade, e $\mathrm{L}$, que descreve o impacto do comprimento da vertente (Panagos et al., 2015).

$\mathrm{O}$ atributo profundidade do vale é baseado na distância vertical entre os cumes das áreas mais elevadas e as linhas de contorno de profundidade. Segundo Meinhardt et al. (2015), a profundidade do vale é diretamente proporcional à suscetibilidade, sendo considerada alta para vales com profundidades superiores a $100 \mathrm{~m}$.

\section{Inventário de Cicatrizes de Movimentos de Massa}

Estes são os dados de entrada que auxiliam a entender o padrão dos atributos do terreno quando da ocorrência dos movimentos de massa. O inventário de cicatrizes do evento ocorrido em 05 de janeiro de 2017 foi realizado por meio de identificação visual a partir de imagens disponíveis no programa Google Earth, as quais apresentavam resolução espacial mais adequada para este tipo de mapeamento, dentre aquelas disponibilizadas de maneira gratuita. As imagens utilizadas correspondem aos dias 06 e 24 de agosto de 2017, e são as mais próximas temporalmente do evento ocorrido.

Foram mapeadas 297 cicatrizes, distribuídas entre os municípios de São Francisco de Paula e Riozinho, as quais abrangem aproximadamente 1 $\mathrm{km}^{2}$. A maioria das cicatrizes apresentou largura menor do que $15 \mathrm{~m}$ e comprimento próximo a 200 $\mathrm{m}$, sendo a maior representada por um complexo de cicatrizes interligadas, com área de 4 ha. A orientação do terreno é composta predominantemente por faces planas e faces sul (S, SE e SO). Os vetores correspondentes às cicatrizes foram transformados para o formato raster e, assim, extraído um ponto por píxel. Os pontos obtidos foram utilizados como amostras de áreas com ocorrência de movimentos de massa.

\section{Amostragem}

O conjunto amostral foi formado por pontos com e sem ocorrência de movimentos de massa. Os pontos relativos à presença de cicatrizes foram extraídos a partir do inventário, resultando em
19.659 píxeis, para o MDE ALOS-PALSAR, e 3.407 píxeis, para o MDE ASTER GDEM.

Para a seleção das amostras de não ocorrência, foram consideradas duas áreas distintas, as quais abarcam o inventário (Figura 4). A seleção de duas áreas para amostragem foi realizada com o intuito de avaliar e demonstrar a influência da representatividade da amostragem no processo de modelagem. Nesse sentido, as áreas amostradas abrangem a área que contém o conjunto de cicatrizes de movimentos de massa, porém variam em tamanho: uma das áreas é mais restritiva, abrange $125 \mathrm{~km}^{2}$, enquanto a outra possui uma área de 386 km².

Foram desconsideradas as áreas do inventário e obtidos pontos aleatórios de modo a representar as áreas sem movimentos de massa. A quantidade de pontos correspondentes às áreas de não ocorrência é igual ao número de pontos com cicatrizes, de acordo com cada MDE, visando aumentar o comprometimento dos modelos em buscar limiares para a separação das classes de suscetibilidade.

Obtidos os dois conjuntos amostrais, e considerando a grande quantidade de píxeis do MDE ALOS-PALSAR, foram aplicados dois métodos de redução de amostras, a fim obter conjuntos menores para a etapa de treinamento dos modelos (diminuindo o custo computacional). As reamostragens foram realizadas a partir do reordenamento dos valores de cada atributo e seleção de um valor a cada $x$ itens. Foram utilizados dois valores para $x$, 50 e 80 .

Os conjuntos amostrais foram subdivididos em amostras de treinamento (21\%, para reamostragem $x=50$ e $14 \%$, para $x=80)$, de validação cruzada (44\% e $46 \%$ ) e de teste (35\% e $40 \%$ ).

A validação cruzada foi realizada apenas para o modelo RNA, a fim de evitar o superajustamento do modelo, enquanto que para RF foram utilizadas somente as amostras correspondentes a treinamento e teste. Foram obtidos oito conjuntos amostrais, dos quais quatro conjuntos de dados foram extraídos do MDE ALOS-PALSAR e quatro do MDE ASTER GDEM. As amostras serviram como dados de entrada para a modelagem realizada a partir de RNA e RF.

\section{Modelagem e Análise Espacial das Áreas Suscetíveis}

Foi realizada a modelagem utilizando o algoritmo RF, desenvolvido com a linguagem de programação Python, e a RNA com o algoritmo retropropagativo, desenvolvido no programa 
MATLAB. O RF é um método ensemblelearning, que seleciona de maneira aleatória percentuais dos dados de entrada e os separa em subconjuntos.

Para cada sub-amostra é construída uma árvore de decisão e o valor estimado é referente à média da predição das árvores. RF gera um modelo de regressão e estima a relevância dos atributos do terreno (Breiman, 2001).

O número de árvores e as suas profundidades foram avaliados com valores de 5 até 50 , variando 5, para ambos os parâmetros. O índice de Gini Impurity $(\Delta \mathrm{I})$ foi selecionado como critério para

partição dos nós das árvores (Equação 1).

$$
\Delta I=G(\tau)-p_{l} G\left(\tau_{l}\right)-p_{r} G\left(\tau_{r}\right)
$$

Em que: $\Delta \mathrm{I}$ quantifica a diminuição do índice de Gini, após a divisão (impureza Gini); G( $\tau$ ) é o valor do índice de Gini para o nó, antes da divisão; $p_{r}$ é a probabilidade das predições das classes para o nó direito $\left(\tau_{\mathrm{r}}\right)$, $\mathrm{p}_{\mathrm{l}}$ é a probabilidade das predições das classes para o nó esquerdo $\tau_{1}$; $\mathrm{G}\left(\tau_{\mathrm{r}}\right)$ é o valor do índice de Gini para o nó direito $\left(\tau_{\mathrm{r}}\right)$ e $\mathrm{G}\left(\tau_{\mathrm{l}}\right)$ é o valor do índice de Gini para o nó esquerdo.

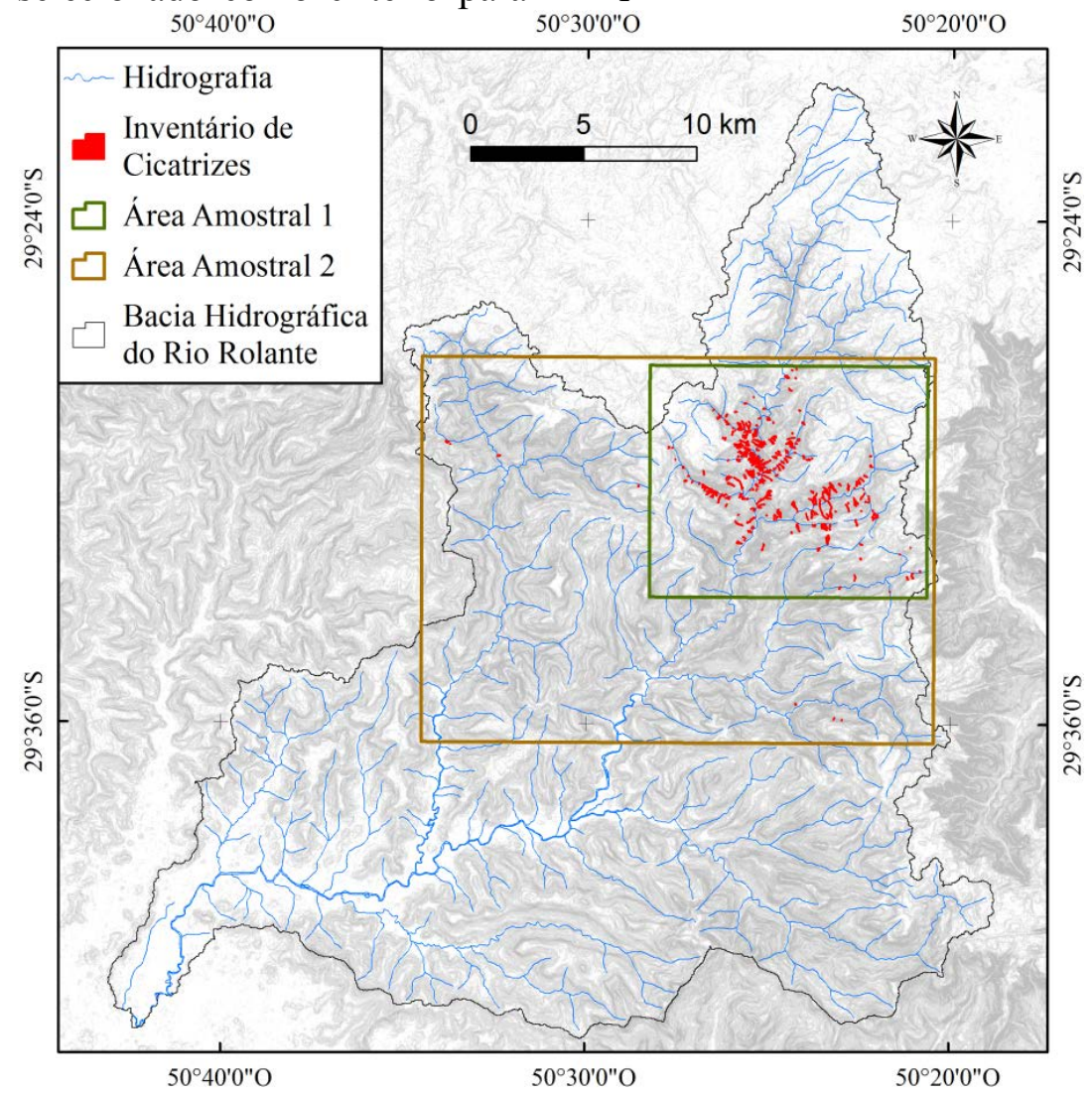

Figura 4 - Área amostral restritiva (área 1) e abrangente (área 2) para coleta de amostras de não ocorrência de movimentos de massa.

Quanto às RNA, a etapa de treinamento foi realizada pelo método retropropagativo com múltiplas camadas (Eq. 2) (Rumelhart et al., 1986), usando a Regra Delta (Widrow \& Hoff, 1960) para atualização dos pesos sinápticos da rede e a função de ativação sigmoidal.

Após o treinamento, foi realizada uma validação cruzada, a fim de evitar o superajustamento do modelo. Foram testadas diversas configurações de modelo, com variação do conjunto de atributos de entrada e do número de neurônios na camada oculta. As variáveis de entrada foram excluídas de maneira sistemática, a partir do Relative Contribution Index (Oliveira et al., 2015).
Foram consideradas 15 iterações e 15.000 ciclos de aprendizagem, caso o modelo não atinja o limiar de convergência, para cada configuração do modelo.

$$
y=f_{s}\left(\sum_{h} w_{s} f_{h}\left(\sum_{e} w_{h} x+b_{h}\right)+b_{s}\right)+e_{s}
$$

Em que: $x$ e y são as matrizes com as entradas (e) e as saídas (s), respectivamente; $w h, b h, w s, b s$ são os pesos sinápticos $(w)$ e os biases $(b)$ das camadas interna $(h)$ e de saída (s); fh e $f s$ são as funções de ativação da camada interna e de saída, respectivamente; $e_{s}$ é o erro esperado na camada de saída. A análise do desempenho dos modelos foi realizada a partir da acurácia (Area Under the 
ROC Curve - AUC) e foram selecionados os melhores resultados. Os dados de saída foram trabalhados no programa ArcGIS, de modo a preparar os dezesseis mapas finais. Foi realizada a classificação das imagens em intervalos de suscetibilidade.

Logo, foram realizados testes de proporção utilizando o Teorema Central do Limite, considerando-se um nível de significância de $5 \%$, ou seja, o intervalo de confiança foi de 95\%. Este teste está baseado na existência de duas populações que representam determinada característica e uma hipótese que afirma que as proporções são iguais, ou seja,

$$
H_{0}: p_{1}=p_{2} \text {. }
$$

Assim, foi realizado o teste de proporção considerando-se a quantidade de amostras (n) e a AUC (p), conforme a Eq. 3 (Morettin \& Bussab,
2011):

$$
Z=\frac{p_{1}-p_{2}}{\sqrt{\frac{p_{1\left(1-p_{1}\right)}}{n_{1}}+\frac{p_{1\left(1-p_{1}\right)}}{n_{2}}}}
$$

Em que: $p$ representa o valor da AUC; $n$ representa a quantidade de amostras; $\mathrm{Z}$ representa o valor da região crítica. Como este teste foi bilateral, se $Z$ apresenta valores entre -1,96 e 1,96, não há razões para discordar que $\mathrm{p}_{1}=\mathrm{p}_{2}$. Caso contrário, rejeitamos a hipótese nula.

Assim, os testes de proporção foram realizados comparando-se os pares: RF e RNA, MDE ALOS-PALSAR e MDE ASTER GDEM, áreas amostrais entre si e processos de reamostragem. A cada comparação realizada, foram obtidos oito cenários, os quais demonstraram similaridade ou não entre as proporções.

\section{RESULTADOS E DISCUSSÃO}

As variáveis explicativas foram extraídas dos MDEs e utilizadas como dados de entrada para os modelos de RNA e RF. Foram calculados os percentuais de importância das variáveis de acordo com cada método (RNA e RF), cada MDE (ALOS-PALSAR e ASTER GDEM) e cada área amostral, considerando-se o método de reamostragem utilizado ( $x=50$ e $x=80$ ).

Nos modelos de RNA, a variável que apresentou maior importância, quanto ao MDE ALOS-PALSAR, foi a altitude (Tabela 1). Em diversos estudos, a altitude é apresentada como um dos fatores mais eficazes para modelar a ocorrência de movimentos de massa (Kawabata \& Bandibas, 2009; Chen et al., 2017). Chen et al. (2017) utilizaram as RNA, entre outros métodos, para modelar as áreas suscetíveis, considerando 11 parâmetros, com destaque para a altitude. Kawabata \& Bandibas (2009) perceberam que a remoção da altitude causa uma redução em mais de $20 \%$ no valor da AUC. $\mathrm{O}$ segundo fator com maior influência foi alternado entre fator LS (área 1 com reamostragem $x=50$ ), declividade (área $1, x=80$ ) e profundidade do vale (área 2, $x=50$ e $x=80$ ).

Na modelagem com o MDE ASTER GDEM, a profundidade do vale foi a variável mais relevante e a altitude apresentou a segunda maior importância, havendo alternância quanto à área 2 com reamostragem $x=50$. Vales com profundidades entre 100 e 200 metros apresentaram maior número de ocorrência de movimentos de massa, o mesmo foi demonstrado em Meinhardt et al. (2015). O somatório das importâncias das variáveis profundidade do vale, altitude e declividade apresentou valores entre $91 \%$ e $97 \%$, o que demonstra que esses três atributos foram os que mais influenciaram na modelagem por RNA com MDE ASTER GDEM.

Tabela 1. Importância dos atributos de terreno nos modelos de RNA.

\begin{tabular}{c|c|c|c|c|c|c|c|c}
\hline \multirow{2}{*}{} & \multicolumn{3}{|c|}{ ALOS-PALSAR } & \multicolumn{3}{c}{ ASTER GDEM } \\
\cline { 2 - 8 } & \multicolumn{2}{|c|}{ Área 1 } & \multicolumn{2}{c}{ Área 2 } & \multicolumn{2}{c}{ Área 1 } & \multicolumn{2}{c}{ Área 2 } \\
\cline { 2 - 9 } & $\boldsymbol{x}=\mathbf{5 0}$ & $\boldsymbol{x}=\mathbf{8 0}$ & $\boldsymbol{x}=\mathbf{5 0}$ & $\boldsymbol{x}=\mathbf{8 0}$ & $\boldsymbol{x}=\mathbf{5 0}$ & $\boldsymbol{x}=\mathbf{8 0}$ & $\boldsymbol{x}=\mathbf{5 0}$ & $\boldsymbol{x}=\mathbf{8 0}$ \\
\hline Altitude & $37 \%$ & $34 \%$ & $32 \%$ & $38 \%$ & $35 \%$ & $38 \%$ & $41 \%$ & $43 \%$ \\
\hline Declividade & $17 \%$ & $24 \%$ & $18 \%$ & $19 \%$ & $19 \%$ & $15 \%$ & $10 \%$ & $10 \%$ \\
\hline Curvatura Horizontal & $04 \%$ & $06 \%$ & $05 \%$ & $06 \%$ & $00 \%$ & $01 \%$ & $01 \%$ & $00 \%$ \\
\hline Curvatura Vertical & $02 \%$ & $02 \%$ & $03 \%$ & $02 \%$ & $01 \%$ & $00 \%$ & $01 \%$ & $00 \%$ \\
\hline Relevo Sombreado & $06 \%$ & $02 \%$ & $10 \%$ & $08 \%$ & $04 \%$ & $04 \%$ & $04 \%$ & $01 \%$ \\
\hline Fator LS & $20 \%$ & $21 \%$ & $13 \%$ & $05 \%$ & $01 \%$ & $02 \%$ & $02 \%$ & $02 \%$ \\
\hline Profundidade de Vale & $14 \%$ & $11 \%$ & $19 \%$ & $21 \%$ & $40 \%$ & $40 \%$ & $40 \%$ & $44 \%$ \\
\hline
\end{tabular}


As curvaturas foram as variáveis menos importantes, as quais somadas representaram menos de $2 \%$ de importância na modelagem com o MDE ASTER GDEM, e entre 6\% e 8\% com MDE ALOS-PALSAR. As curvaturas tendem a ser os parâmetros com menor peso nas modelagens, como verificado em Chen et al. (2017), que utilizaram o índice Kappa para avaliar a importância das variáveis, e obtiveram valores menores do que 0,09 para ambas as curvaturas.

Pourghasemi \& Rahmati (2018) compararam 10 métodos de aprendizado de máquinas utilizando 11 parâmetros, e ambas as curvaturas demonstraram menor importância. Meinhardt et al. (2015) perceberam que a exclusão das curvaturas gerava um acréscimo na acurácia dos seus modelos.
A modelagem utilizando o método RF apresentou o fator LS como o atributo mais importante quanto ao MDE ALOS-PALSAR, sendo o único a apresentar valores acima de $18 \%$ (entre $39 \%$ e $43 \%$ ) nos quatro modelos considerados (Tabela 2). Juntamente com os fatores altitude e profundidade do vale, concentraram entre $69 \%$ e $73 \%$ da importância. Na modelagem com MDE ASTER GDEM, os fatores mais influentes foram profundidade do vale e fator LS, os quais apresentaram juntos $54 \%$ e $72 \%$ da importância quanto à área 1 , $\mathrm{x}=50$ e $\mathrm{x}=80$, respectivamente. A área 2 destacou, além dos fatores profundidade do vale e fator LS, o atributo altitude, que somados apresentam valores de importância entre $71 \%$ e $74 \%$.

Tabela 2 - Importância dos atributos do terreno no modelo RF.

\begin{tabular}{c|c|c|c|c|c|c|c|c}
\hline \multirow{2}{*}{} & \multicolumn{3}{|c|}{ ALOS-PALSAR } & \multicolumn{3}{c}{ ASTER GDEM } \\
\cline { 2 - 9 } & \multicolumn{2}{|c|}{ Área 1 } & \multicolumn{2}{c|}{ Área $\mathbf{2}$} & \multicolumn{2}{c}{ Área 1 } & \multicolumn{2}{c}{ Área $\mathbf{2}$} \\
\cline { 2 - 9 } & $\boldsymbol{x}=\mathbf{5 0}$ & $\boldsymbol{x}=\mathbf{8 0}$ & $\boldsymbol{x}=\mathbf{5 0}$ & $\boldsymbol{x}=\mathbf{8 0}$ & $\boldsymbol{x}=\mathbf{5 0}$ & $\boldsymbol{x}=\mathbf{8 0}$ & $\boldsymbol{x}=\mathbf{5 0}$ & $\boldsymbol{x}=\mathbf{8 0}$ \\
\hline Altitude & $17 \%$ & $17 \%$ & $17 \%$ & $16 \%$ & $09 \%$ & $05 \%$ & $21 \%$ & $21 \%$ \\
\hline Declividade & $00 \%$ & $06 \%$ & $06 \%$ & $06 \%$ & $12 \%$ & $09 \%$ & $13 \%$ & $12 \%$ \\
\hline Curvatura Horizontal & $09 \%$ & $08 \%$ & $07 \%$ & $06 \%$ & $09 \%$ & $04 \%$ & $04 \%$ & $09 \%$ \\
\hline Curvatura Vertical & $09 \%$ & $09 \%$ & $07 \%$ & $08 \%$ & $08 \%$ & $05 \%$ & $07 \%$ & $08 \%$ \\
\hline Relevo Sombreado & $09 \%$ & $08 \%$ & $07 \%$ & $08 \%$ & $08 \%$ & $03 \%$ & $02 \%$ & $00 \%$ \\
\hline Fator LS & $43 \%$ & $42 \%$ & $39 \%$ & $40 \%$ & $12 \%$ & $11 \%$ & $34 \%$ & $27 \%$ \\
\hline Profundidade de Vale & $13 \%$ & $10 \%$ & $17 \%$ & $16 \%$ & $42 \%$ & $61 \%$ & $19 \%$ & $23 \%$ \\
\hline
\end{tabular}

A declividade é considerada como um dos fatores mais relacionados com a ocorrência de movimentos de massa (Pradhan \& Lee, 2010; Oliveira et al., 2018; Pourghasemi et al., 2018). Entretanto, a modelagem do MDE ALOSPALSAR por RF apresentou a declividade como atributo menos influente no modelo. Para Kawabata \& Bandibas (2009), a declividade apresentou pouca relevância, em que sua exclusão da modelagem modificou levemente a AUC (de 93,68\% para 92,71\%, ou seja, em menos de $1 \%$ ), pois a geologia apresentou maior influência no modelo.

Ao se analisar dois fatores com informações semelhantes, tende-se a considerar um com maior peso, ao passo que o outro recebe um peso menor. Assim, nesta modelagem, o atributo com maior importância foi o fator LS, enquanto a declividade foi considerada com menor importância. $\mathrm{O}$ fator LS demonstra o efeito da topografia na erosão do solo, combinando o efeito da inclinação da encosta (declividade) e o comprimento da vertente. Ou seja, a declividade e o fator LS são altamente correlacionados, pois há informação comum entre esses atributos, sendo essa a provável causa do resultado obtido, o qual apresentou destaque para a declividade nas RNA e para o fator LS no RF.

De modo geral, na modelagem a partir de RF, a curvatura vertical, a curvatura horizontal e o relevo sombreado foram os atributos menos importantes após a declividade. Os percentuais variaram de $0 \%$ (variável excluída do modelo) a $9 \%$. Os valores de declividade não superaram os $13 \%$. Com isso, notou-se que as variáveis que apresentaram grau de importância significativo (acima de 20\%) em ao menos dois modelos foram altitude, fator LS e profundidade do vale com o MDE ASTER GDEM.

As acurácias (AUC) obtidas nos modelos de RNA e RF consideram a melhor configuração para cada combinação de dados de entrada (considerando os dois MDEs, as duas áreas amostrais e as duas técnicas de reamostragem, totalizando 16 mapas de suscetibilidade), apresentados na tabela 3. Estudos consideram uma boa 
AUC valores superiores a 0,8 (Pradhan \& Lee, 2010; Dou et al., 2015), neste estudo, independentemente do conjunto de amostras utilizados e da complexidade das RNA ou do modelo RF, a acurácia AUC apresentou valores entre 0,88 e 0,94 , indicando um elevado grau de acerto no mapeamento de suscetibilidade a movimentos de massa.

Tabela 3 - Acurácia (AUC) dos modelos RNA e RF.

\begin{tabular}{|c|c|c|c|c|c|c|}
\hline & \multirow[b]{2}{*}{ Área } & \multirow[b]{2}{*}{ Amostragem } & \multicolumn{2}{|c|}{ RNA } & \multicolumn{2}{|r|}{$\mathbf{R F}$} \\
\hline & & & AUC & $\begin{array}{c}\mathrm{N}^{0} . \\
\text { Neurônios } \\
\end{array}$ & AUC & $\begin{array}{l}\mathbf{N}^{0} \text {. Árvores / } \\
\text { Profundidade }\end{array}$ \\
\hline \multirow{4}{*}{ 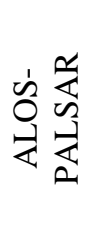 } & \multirow{2}{*}{1} & 50 & 0,8902 & 11 & 0,9124 & 45 / 35 \\
\hline & & 80 & 0,8797 & 05 & 0,9001 & $45 / 50$ \\
\hline & \multirow{2}{*}{2} & 50 & 0,9194 & 13 & 0,9356 & $50 / 25$ \\
\hline & & 80 & 0,9199 & 11 & 0,9296 & $50 / 50$ \\
\hline \multirow{4}{*}{ 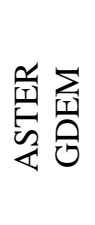 } & \multirow{2}{*}{1} & 50 & 0,8888 & 09 & 0,8807 & 40 / 30 \\
\hline & & 80 & 0,8857 & 05 & 0,8762 & 45 / 05 \\
\hline & \multirow{2}{*}{2} & 50 & 0,9319 & 05 & 0,9224 & 45 / 50 \\
\hline & & 80 & 0,9229 & 13 & 0,9156 & $35 / 10$ \\
\hline
\end{tabular}

De maneira geral, o desempenho do modelo RF foi melhor do que as RNA, apresentando somente dois valores abaixo de 0,9 , semelhante ao observado em Pourghasemi \& Rahmati (2018). Ao analisar de maneira individual cada resultado, verifica-se que o modelo RF apresentou AUC maior do que as RNA com o uso do MDE ALOS-PALSAR, em contrapartida, com o MDE ASTER GDEM, os conjuntos de dados das RNA apresentam AUC levemente maior. A realização do teste de proporção, com nível de significância de 5\%, demonstrou que, em três dos oito cenários, a hipótese de que os índices de acurácia dos dois modelos (RF e RNA) são semelhantes deve ser rejeitada, indicando que o modelo $\mathrm{RF}$ apresentou desempenho superior à RNA no nível de significância do teste.

Entre os MDE, o ALOS-PALSAR resultou em valores de AUC maiores quando comparado ao uso do MDE ASTER GDEM em todos os resultados referentes ao RF. Quanto à modelagem por RNA, a área 1 , reamostragem por $x=50$, e a área $2, x=80$, apresentaram valores muito próximos entre os modelos.

Quanto às outras duas configurações, o MDE ASTER GDEM apresentou AUC levemente maior, semelhante ao apresentado por Arnone et al. (2016) em que foram testados MDE com resoluções de $10 \mathrm{~m}$ e de $30 \mathrm{~m}$ e percebeu-se uma diferença de 0,08 entre os índices AUC, 0,87 para o MDE com melhor resolução e 0,79 para o MDE de 30 metros.

A acurácia dos mapas resultantes da 1,00) quando comparada à área 1 (Figura 5), modelagem usando os MDEs ALOS-PALSAR e ASTER GDEM não tem uma diferença maior do que 0,03. O MDE ASTER GDEM apresentou um bom desempenho com o uso de um conjunto amostral menos numeroso do que o MDE ALOS-PALSAR.

O teste de proporção realizado demonstrou que não se pode rejeitar a hipótese de superioridade do MDE ALOS-PALSAR somente em duas das oito comparações, enquanto nas demais essa hipótese deve ser rejeitada, indicando que as acurácias podem ser equivalentes para o uso dos dois MDEs. Cabe ressaltar, no entanto, que a resolução espacial do mapa final é inferior no caso do MDE ASTER GDEM, não se adequando para escalas superiores a 1:50.000.

Houve distinção quanto às áreas amostrais, visto que a área 2 apresentou maiores AUC. A área 1 representou cerca de um terço da área amostral 2, o que resulta em uma maior restrição quanto à representatividade dos atributos do terreno, uma vez que abrange menos áreas diferentes, como fundos de vales, por exemplo. A maior abrangência da área $2 \mathrm{fez}$ com que houvessem pontos amostrais referentes a áreas sem cicatrizes com maior variação dos valores e representatividade. Em todos os cenários realizados no teste de proporção, se aceita a hipótese de que a área 2 demonstra melhor desempenho do que a área 1.

A área 2 tende a superestimar áreas de alta suscetibilidade a movimentos de massa $(0,90-$ 95, 2019 789 
principalmente para o RF (Figuras 5B.3a, 5B.3b, 5B.4a, 5B.4b). A área 1 apresentou as classes de maneira contínua, aumentando as áreas de suscetibilidade em fundos de vale. A
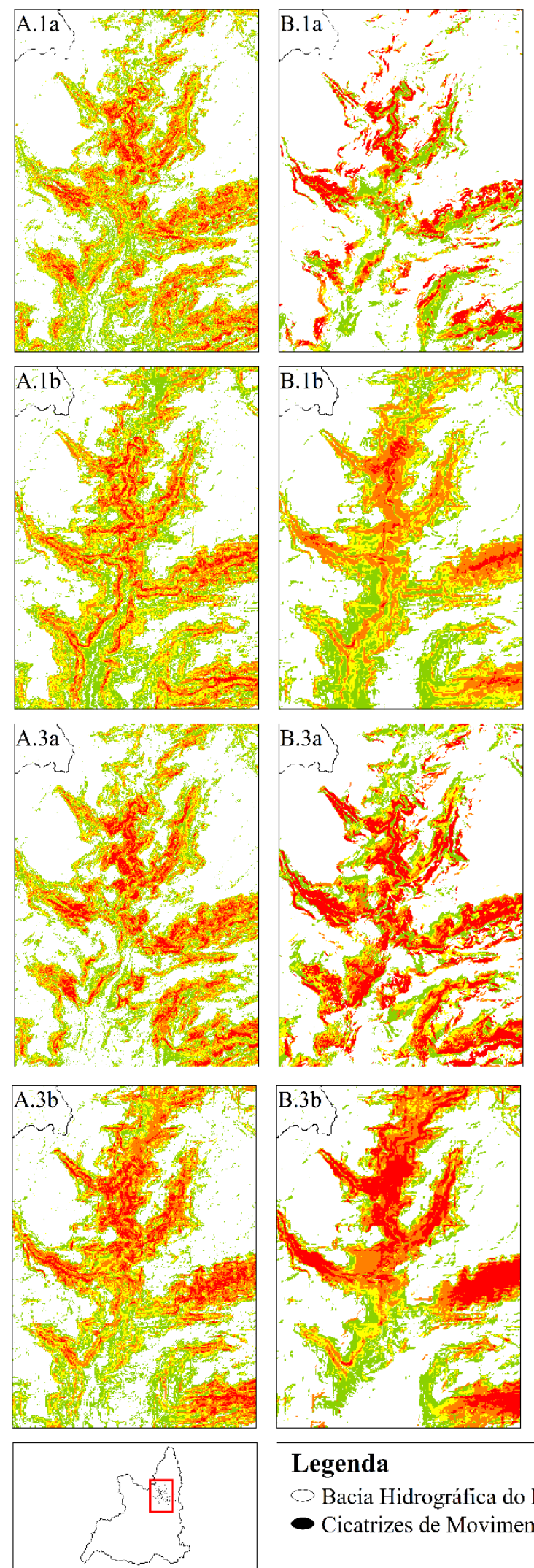

Legenda área 2, quanto ao MDE ALOS-PALSAR apresentou os resultados mais coerentes para as áreas de fundo de vale, tanto para RNA, quanto para RF, com valores baixos de suscetibilidade.
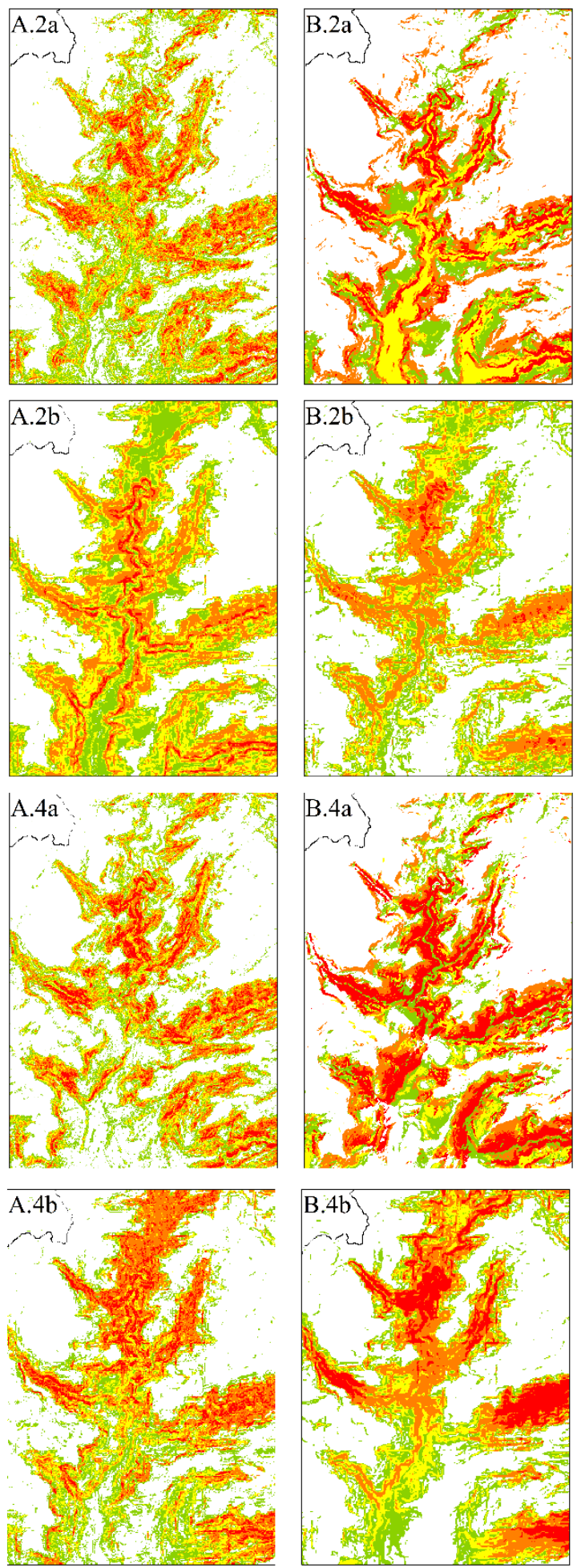

Bacia Hidrográfica do Rio Rolante

Nível de Suscetibilidade
$<0,25$
$0,25-0,50$

$0,50-0,70$

$0,70-0,90$

$0,90-1,00$

Figura 5 - Níveis de suscetibilidade conforme o melhor modelo para cada conjunto de dados. Em que A representa o método RNA; B representa RF; 1 representa a área 1 com reamostragem $x=50$; 2 representa a área 1 com reamostragem $\mathrm{x}=80$; 3 representa a área 2 com reamostragem $\mathrm{x}=50$; 4 representa a área 2 com reamostragem $\mathrm{x}=80$; a representa ALOS-PALSAR; b representa AS. 
Não foram observadas diferenças significativas quanto ao uso das reamostragem $x=50$ ou $x=80$, as quais apresentaram valores similares de acurácia. O teste de proporção demonstrou que em sete de oito cenários não se pode rejeitar a hipótese de que são equivalentes, com nível de significância de 5\%. Realizar este tipo de reamostragem, de modo a exigir uma menor capacidade de processamento computacional, se demonstrou adequada e representativa, pois não houve perda de acurácia com a seleção mais rigorosa de amostras para o treinamento.

Considerando o MDE ALOS-PALSAR, houve uma redução entre $7 \%$ e $8 \%$ no tempo de processamento dos dados, enquanto que para modelagem com MDE ASTER GDEM, a redução foi de 3\% a $4 \%$.

Os resultados da figura 5 mostram mapas distintos entre si, ainda que todos os 16 resultados apresentem valores semelhantes de acurácia. Essa diferença revela que, de acordo com o conjunto amostral e o modelo utilizado, o relacionamento entre os atributos do terreno e os níveis de suscetibilidade resultantes do processo de modelagem podem ser bem distintos. Isso é observado em destaque no mapa de diferenças (Figura 6), obtido pela subtração dos dois mapas de maior acurácia: (MDE ASTER GDEM, área 2, reamostragem por $x=50$, a partir das RNA) - (MDE ALOSPALSAR, área 2, reamostragem por $x=50$, a partir do RF).

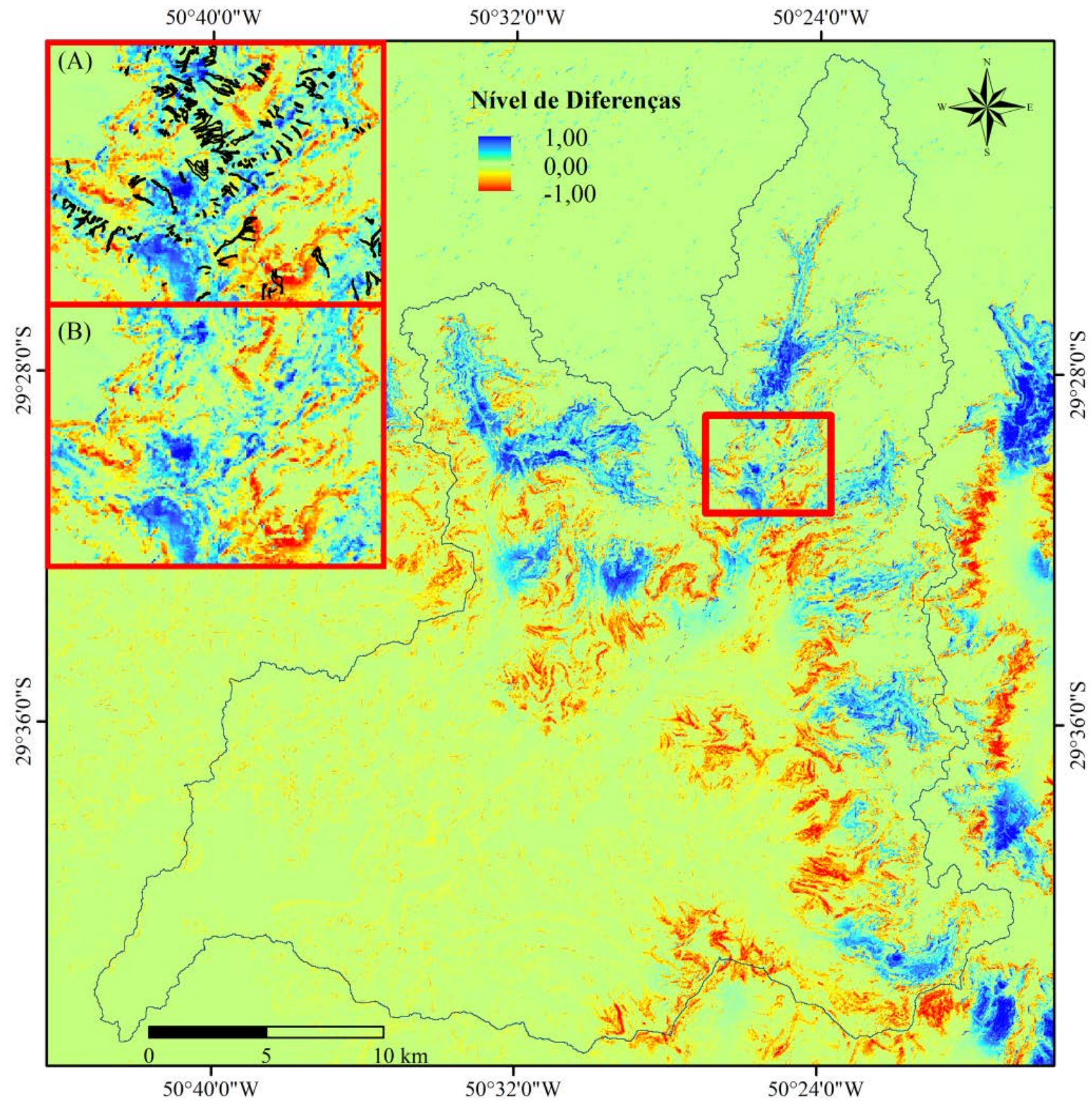

Figura 6 - Mapa de diferença entre os dois mapas de maior acurácia: A) zoom na área com concentração de cicatrizes e sua distribuição sobre o mapa de diferenças; B) zoom na área com concentração de cicatrizes sem sobreposição. 
O mapa de diferença mostra que as áreas com maiores variações quanto aos valores de suscetibilidade estão nas encostas e nas linhas de escarpa erosiva.

A figura 6A mostra um zoom na área com concentração de cicatrizes, com sobreposição dos polígonos, e a figura $6 \mathrm{~B}$ sem considerar a sobreposição das cicatrizes. A área destacada apresenta diferenças elevadas em muitas áreas com cicatrizes. As áreas de vale a jusante não sofreram diferenças significativas, a grande maioria apresentou valores de suscetibilidade abaixo de 0,25.

Em função das sensíveis diferenças verificadas nos níveis de suscetibilidade, a escolha do mapa resultante, considerando-se apenas aquele que obteve a maior acurácia, pode não ser a estratégia mais adequada, ainda
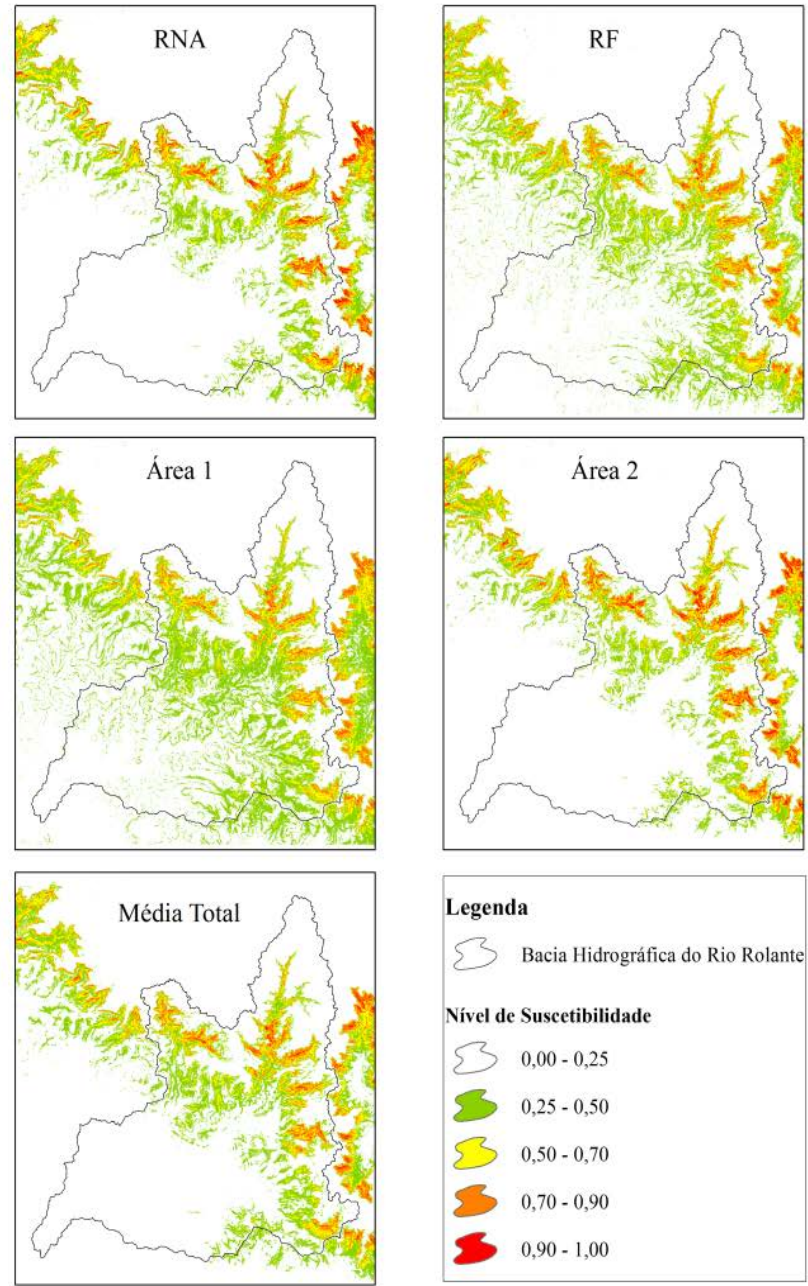

que normalmente seja a decisão mais utilizada. Uma alternativa poderia ser a extração de uma média dos modelos que tenham obtido acurácia satisfatória e equivalente, na tentativa de suavizar tais diferenças e identificar um padrão espacial nas manchas de suscetibilidade.

Os mapas de média, figura 7 , ilustram os modelos (RNA e RF), os MDEs (ALOSPALSAR e ASTER GDEM), as áreas de coleta de amostras (áreas 1 e 2) e os métodos de reamostragem $(x=50$ e $x=80)$. Foi extraída a média geral dos 16 mapas, combinando todas as técnicas testadas. A análise dos resultados mostra um padrão das áreas suscetíveis, com maior similaridade entre os resultados. Essa concordância pode representar uma segurança a mais na escolha do mapa considerado ideal para representar a suscetibilidade.
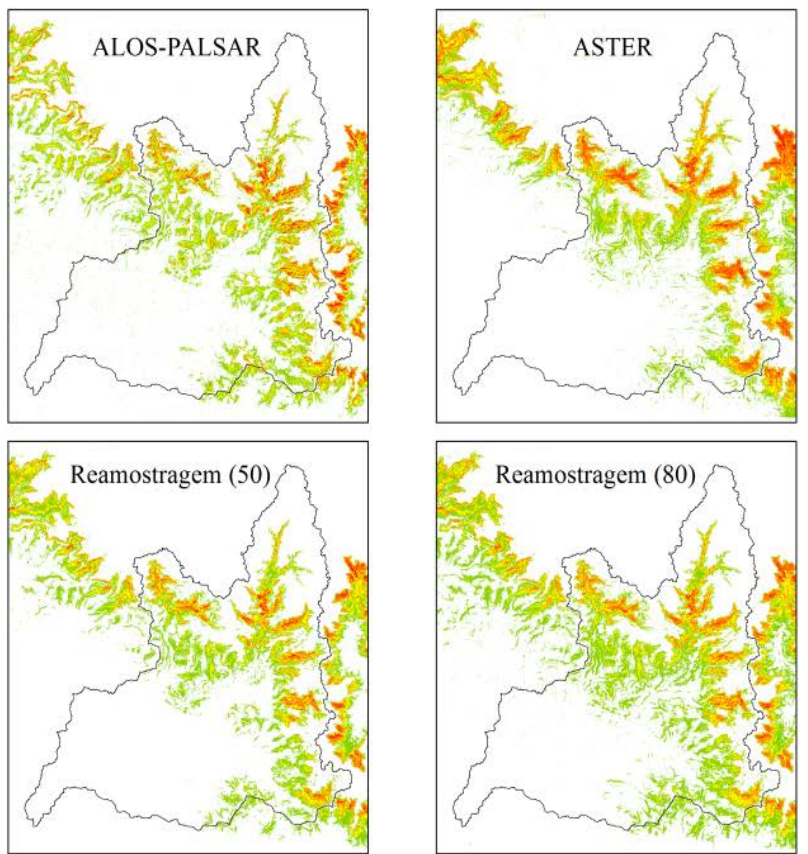

Figura 7 - Média das imagens resultantes para cada configuração de modelo e método de amostragem.

A comparação entre a média dos métodos mostra que as RNA apresentam maiores áreas de alta suscetibilidade $(0,90-1,00)$ do que o RF. O mesmo acontece quanto ao MDE ASTER GDEM, em relação ao MDE ALOS-PALSAR, e quanto a área 2, se comparada à área 1 .
Entretanto, as diferenças verificadas não são tão acentuadas quanto àquelas apresentadas pelos mapas de suscetibilidade da figura 5 .

A análise do desvio padrão do conjunto de imagens resultantes (Figura 8) mostra que as maiores variações estão concentradas nas 
encostas e áreas de maior declividade, justamente as áreas mais suscetíveis. Ainda que todos os modelos indiquem corretamente essas áreas como suscetíveis, os níveis de suscetibilidade variam bastante de um mapa para outro.

Pode-se destacar que a dispersão dos valores de suscetibilidade foi inferior quando utilizada uma área mais abrangente de amostragem (Área 2), indicando que os mapas modelados com base nesse conjunto amostral apresentam maior similaridade entre si, divergindo em níveis de suscetibilidade apenas na linha da escarpa erosiva. Esses resultados reforçam que a abrangência da área de coleta de amostras influencia de forma positiva na generalização dos modelos, contribuindo para uma melhor representação da realidade. O maior desvio padrão das imagens ALOS-PALSAR em relação àquelas do ASTER GDEM pode ser explicado pela resolução espacial, pois MDEs
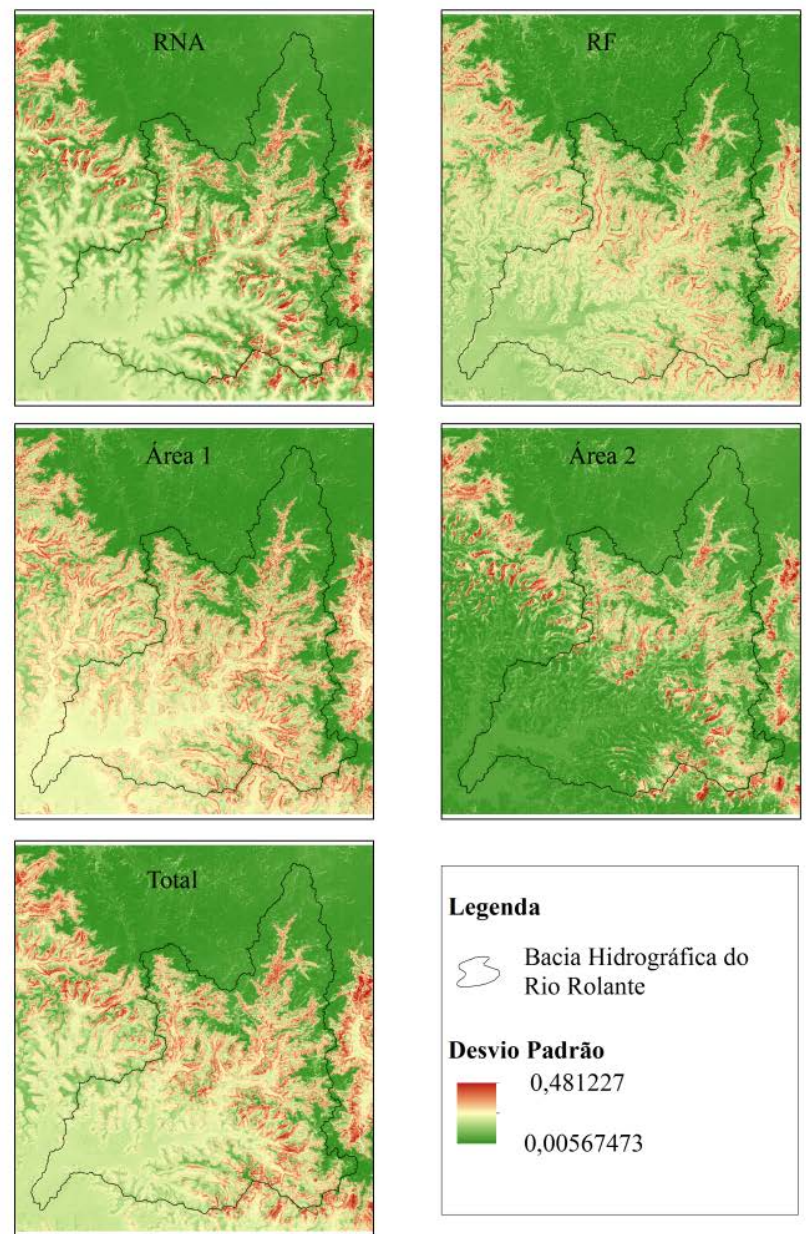

mais detalhados apresentam maior variação de seus valores, consequentemente, os resultados do modelo tendem a apresentar maior dispersão dos valores.

O uso de RNA e de RF demonstrou ser eficaz para o mapeamento de áreas suscetíveis a movimentos de massa. O MDE ALOSPALSAR demonstrou AUC levemente maior, porém, ambos os MDEs apresentaram acurácia elevada. Definir uma área amostral de maneira mais abrangente mostrou resultados melhores do que áreas mais restritivas. Enquanto isso, as reamostragens não apresentaram padrão nos resultados, ambos apresentaram AUC elevada. Utilizar a reamostragem de $x=80$ apresenta-se como uma boa estratégia para diminuir a exigência de processamento quando da calibração dos modelos. Assim, os resultados se demonstraram satisfatórios, com mapeamentos adequados.
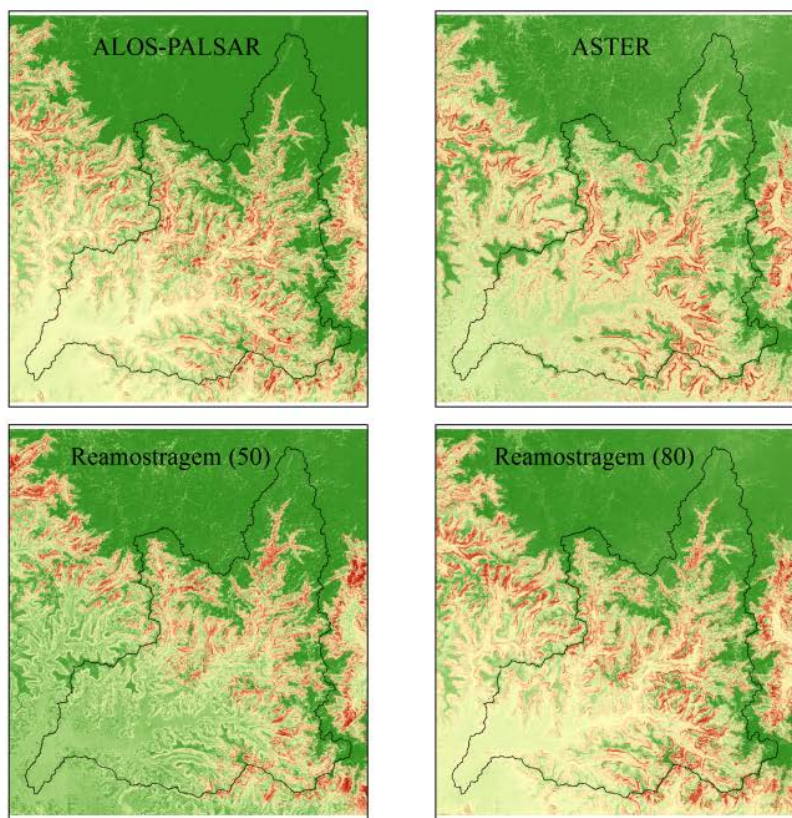

Figura 8 - Desvio padrão das imagens resultantes para cada configuração de modelo e método de amostragem.

\section{CONCLUSÕES}

A comparação entre diferentes métodos de modelagem de áreas suscetíveis a movimentos de massa demonstrou que a variável morfométrica do terreno mais importante nas
RNA foi a altitude, com valores acima de $30 \%$. Enquanto no RF foi o fator LS, que somado aos parâmetros altitude e profundidade do vale apresentaram valores de importância entre 69\% 
e 73\%. Quando o fator LS apresenta alto valor de importância, a declividade demonstra-se pouco importante, devido presença de informações repetidas nestes fatores. As curvaturas demonstraram pouca importância nas modelagens.

A realização do teste de proporção demonstrou que não se pode rejeitar a hipótese de que os métodos RF e RNA são equivalentes estatisticamente em cinco cenários entre oito. $\mathrm{O}$ MDE ALOS-PALSAR demonstrou AUC levemente maior e se aceita a hipótese de que em dois cenários dentre oito o MDE ALOSPALSAR apresentou melhor desempenho, enquanto nos demais não se rejeita a hipótese de os MDEs serem equivalentes.

Definir a área amostral de maneira mais abrangente mostrou resultados melhores do que áreas mais restritivas quanto à acurácia e à capacidade de generalização dos modelos, representando de maneira mais adequada a suscetibilidade em áreas de fundo de vales, por exemplo. Com nível de significância de 5\%, o teste de proporção demonstrou em todos os cenários que não se rejeita a hipótese de a área 2 apresentar desempenho melhor que a área 1.

As reamostragens não apresentaram padrão nos resultados. A partir do teste de proporção, em sete de oito cenários não se pode rejeitar a hipótese de que são equivalentes. A redução do conjunto amostral de treinamento diminuiu o tempo de processamento entre $3 \%$ e $4 \%$ para o MDE ASTER GDEM, e entre $7 \%$ e $8 \%$ para o MDE ALOS-PALSAR, sem interferir de modo significativo na acurácia dos mapas. Assim, estes processos de amostragem demonstram-se como uma alternativa para grandes conjuntos amostrais. Por fim, conclui-se que o uso de RNA e de RF se demonstraram eficazes para o mapeamento de áreas suscetíveis a movimentos de massa, apresentando acurácias próximas ou superiores a $90 \%$.

\section{AGRADECIMENTOS}

O presente trabalho foi realizado com apoio: i) da Coordenação de Aperfeiçoamento de Pessoal de Nível Superior - Brasil (CAPES) - Código de Financiamento 001; ii) da Fundação de Amparo à Pesquisa do Estado do Rio Grande do Sul - FAPERGS, com apoio financeiro via Edital 01/2017 ARD, processo 17/2551-0000894-4.

\section{REFERÊNCIAS}

ADA, M. \& SAN, T. Comparison of machine-learning techniques for landslide susceptibility mapping using twolevel random sampling (2LRS) in Alakir catchment area, Antalya, Turkey. Nat Hazards, v. 90, p. 237-263, 2018.

ADITIAN, A.; KUBOTA, T.; SHINOHARA, Y. Comparison of GIS-based landslide susceptibility models using frequency ratio, logistic regression, and artificial neural network in a tertiary region of Ambon, Indonesia. Geomorphology, v. 318, p. 101-111, 2018.

ARNONE, E.; FRANCIPANE, A.; SCARBACI, A.; PUGLISI, C.; NOTO, L.V. Effect of raster resolution and polygonconversion algorithm on landslide susceptibility mapping. Environmental Modelling and Software, v. 84, p. 467-481, 2016.

ASTER GDEM Validation Team. ASTER Global Digital Elevation Model Version 2 - Summary of Validation Results. Disp. em: https://ssl.jspacesystems.or.jp/ersdac/ GDEM/ver2Validation/Summary_GDEM2_validation_report final.pdf. 2011.

BRASIL. Lei 12.608, de 10 de Abril de 2012. Institui a Política Nacional de Proteção e Defesa Civil PNPDEC. 2012.

BREIMAN, L. Random Forests. Machine Learning, v. 45, p. 5-32, 2001.

CEPED UFSC - CENTRO DE ESTUDOS E PESQUISAS EM ENGENHARIA E DEFESA CIVIL, UNIVERSIDADE FEDERAL DE SANTA CATARINA. Atlas Brasileiro de Desastres Naturais - 1991 a 2012. Volume Brasil. 2. ed. rev. amp. Florianópolis: CEPED UFSC, 127 p., 2013.

CHEN, W.; POURGHASEMI, H. R.; KORNEJADY, A.; ZHANG, N. Landslide spatial modeling: Introducing new ensembles of ANN, MaxEnt, and SVM machine learning techniques. Geoderma, v. 305, p. 314-327, 2017.
CHEN, X.; LIU, C.; CHANG, Z.; ZHOU, Q. The relationship between the slope angle and the landslide size derived from limit equilibrium simulations. Geomorphology, v. 253, p. 547-550, 2016.

DAI, F.C. \& LEE, C.F. Landslide characteristics and slope instability modeling using GIS, Lantau Island, Hong Kong. Geomorphology, v. 42, p. 213-228, 2002.

DOU, J.; YAMASTER GDEMISHI, H.; POURGHASEMI, H.R.; YUNUS, A.P.; SONG, X.; XU, Y; ZHU, Z. An integrated artificial neural network model for landslide susceptibility assessment of Osado Island, Japan. Natural Hazards, v. 78, p. 1749 - 1776. 2015.

FROUDE, M. J. \& PETLEY, D. N. Global fatal landslide occurrence from 2004 to 2016. Natural Hazards and Earth System Sciences, v. 18, p. 2161-2181, 2018.

GAMEIRO, S.; QUEVEDO, R.P.; OLIVEIRA, G.G.; RUIZ, L.F.C.; GUASSELLI, L.A. Análise e correlação de atributos morfométricos e sua influência nos movimentos de massa ocorridos na Bacia do Rio Rolante, RS. In: SIMPÓSIO BRASILEIRO DE SENSORIAMENTO REMOTO, XIX, 2019, Santos. Anais... Santos: 2019. v. 17, p. 2880-2883.

JAXA. Japan Aerospace Exploration Agency. Earth Observation Research Center. About ALOS-PALSAR. Disp. em: https://www.eorc.jaxa.jp/ALOS/en/about/palsar.htm.

KAWABATA, D. \& BANDIBAS, J. Landslide susceptibility mapping using geological data, a DEM from ASTER images and an Artificial Neural Network (ANN). Geomorphology, v. 113, p. 97-109, 2009.

MEINHARDT, M.; FINK, M.; TÜNSCHEL, H. Landslide susceptibility analysis in central Vietnam based on an incomplete landslide inventory: Comparison of a new method 
to calculate weighting factors by means of bivariate statistics. Geomorphology, v. 234, p. 80-97, 2015.

METEN, M.; PRAKASHBHANDARY, N.; YATABE, R. Effect of Landslide Factor Combinations on the Prediction Accuracy of Landslide Susceptibility Maps in the Blue Nile Gorge of Central Ethiopia. Geoenvironmental Disasters, v. 2, n. 9, p. 1-17, 2015.

MORETTIN, O.A. \& BUSSAB, W. O. Estatística básica. 7. Ed. São Paulo: Saraiva, 540 p., 2011.

OLIVEIRA, G.G.; GUASSELLI, L.A.; QUEVEDO, R.P.; RUIZ, L.F.C.; BRESSANI, L.A.; RIFFEL, E.S. Identificação e análise de áreas suscetíveis a fluxos de detritos na bacia hidrográfica do Rio Taquari-Antas, RS. Pesquisas em Geociências, v. 45, n. 2, p. 1-25, 2018.

OLIVEIRA, G.G.; PEDROLLO, O.C.; CASTRO, N.M.R. Simplifying artificial neural network models of river basin behaviour by an automated procedure for input variable selection. Engineering Applications of Artificial Intelligence, v. 40, p. 47-61, 2015.

PANAGOS, P.; BORRELLI, P.; MEUSBURGER, K. A New European Slope Length and Steepness Factor (LS-Factor) for Modeling Soil Erosion by Water. Geosciences, v. 5, p. 117126, 2015.

POURGHASEMI, H. R. \& RAHMATI, O. Prediction of the landslide susceptibility: Which algorithm, which precision? Catena, v. 162, p. 177-192, 2018.

POURGHASEMI, H. R.; GAYEN, A.; PARK, S.; LEE, C. W., LEE, S. Assessment of landslide-prone areas and their zonation using logistic regression, LogitBoost, and naïvebayes machine-learning algorithms. Sustainability, v. 10, p. 1-23, 2018.

PRADHAN, B. \& LEE, S. Regional landslide susceptibility analysis using back-propagation neural network model at Cameron Highland, Malaysia. Landslides, v. 7, n. 1, p. 13-30, 2010.
QUEVEDO, R.P.; OLIVEIRA, G.G.; GAMEIRO, S.; RUIZ, L.F.C.; GUASSELLI, L.A. Modelagem de áreas suscetíveis a movimentos de massa com redes neurais artificiais. In: XIX SIMPÓSIO BRASILEIRO DE SENSORIAMENTO REMOTO, 2019, Santos. Anais...Santos: 2019. v. 17, p. $2910-$ 2913.

ROSSATO, M. S. Os Climas do Rio Grande do Sul: variabilidade, tendências e tipologia. Porto Alegre, 2011. 253 p. Tese (Doutorado em Geografia) - Programa de PósGraduação em Geografia, Universidade Federal do Rio Grande do Sul.

RUMELHART, D.E.; HINTON, G.E.; WILLIAMS, R.J. Learning representations by back-propagating errors. Nature, v. 323, p. 533- 536, 1986.

SEMA. Diagnóstico Preliminar: Descritivo dos eventos ocorridos no dia 5 de janeiro de 2017 entre as regiões dos municípios de São Francisco de Paula e Rolante/RS. Secretaria do Ambiente e Desenvolvimento Sustentável, Porto Alegre, 26 p., 2017.

WIDROW, B. \& HOFF, M.E. Adaptive Switching Circuits. In: 1960 IRE WESCON CONVENTION RECORD, New York. IRE Part... New York, 1960, p. 6- 104
Submetido em 2 de abril de 2019 Aceito em 27 de agosto de 2019 